\title{
Consistent allocation of cabinet seats: the Swiss Magic Formula
}

\author{
Reiner Wolff • Yavuz Karagök
}

Received: 1 June 2010 / Accepted: 1 September 2010 / Published online: 23 September 2010

(C) Springer Science+Business Media, LLC 2010

\begin{abstract}
In 1959, the four largest political parties in Switzerland's Federal Assembly established a broad coalition government with a specific allocation of the seven cabinet seats among them. This assignment continued unaltered for 44 years up to 1999. It is, therefore, phrased the 'Magic Formula'. The underlying political paradigm appears to be essentially egalitarian, with a Rawlsian concern for minorities. We thus ask whether the Magic Formula can be implemented by the nucleolus of a weighted voting game for the Swiss government. We provide results over real-valued and integer-valued imputation sets, and for all regular election periods from 1959 to date. It turns out that the Magic Formula is contained in eight out of 11 nucleoli over integer domains between 1959 and 1999, and that it comes very close to the nucleolus in two of the three remaining cases. The game solution likewise predicts in part a major modification of the Magic Formula adopted in 2003.
\end{abstract}

Keywords Fair representation · Nucleolus $\cdot$ Weighted voting games

JEL Classification $\mathrm{C} 71 \cdot \mathrm{D} 63 \cdot \mathrm{D} 72$

\section{Introduction}

How should a given number of cabinet ministries be assigned to a committee of political parties? Which method for allocating cabinet seats can be considered as being just? These are vital questions of parliamentary government. The underlying general issue is that of the distribution of representation among political constituencies (cf. Balinsky and Young 2001). This problem has attracted a lot of theoretical interest, as can be seen, e.g., from the large

R. Wolff $(\bowtie)$

Department of Quantitative Economics, University of Fribourg, Boulevard de Pérolles 90,

1700 Fribourg, Switzerland

e-mail: reiner.wolff@unifr.ch

url: http://www.unifr.ch/mikoek

Y. Karagök

Swiss Confederation, Competition Commission Secretariat, Bern, Switzerland 
volume of literature on the design of voting procedures (cf. the surveys by Brams 1994; Brams and Fishburn 2002; Peleg 2002; also see Laruelle and Valenciano 2008) and on the measurement of the resulting voting power in an electoral committee (for an overview cf. Owen 1995, Chapter 12; Felsenthal and Machover 1998; Holler and Owen 2001). There, fair representation is often associated with the ideal of proportionality. In practice, nevertheless, many procedures for allocating cabinet seats tend to result in a governing coalition of parties which is either center-left or center-right, and often with a strong representation of small pivotal coalition members. A notable and interesting exception, as we shall now see, is the process of government formation in Switzerland, a country with one of the longest democratic traditions in the world.

The Swiss Confederation has a bicameral national parliament. It comprises the larger House of Representatives or so-called National Council and the smaller Senate, the socalled Council of (cantonal) States. Every four years, at the beginning of the term of office of a newly elected National Council, the two chambers meet in joint session as the United Federal Assembly, in order to elect Switzerland's executive government, known as the Federal Council. Already instituted by the 1848 Federal Constitution, the Federal Council has had seven members since. They are elected in separate balloting procedures. In the first two rounds of voting for a Council seat, each parliament member is free to enter a preferred name. Afterwards, the name that gained the least votes in the preceding round will be removed from the ballot. The election ends as soon as an absolute majority of votes is cast for one person. This person may later be re-elected for an indefinite number of four-year terms. When a Federal Councillor resigns from the office ahead of time, the parliament assembles again to fill the vacancy for the remainder of the term.

In 1959, the four largest political parties-in terms of votes in the Federal Assemblyestablished a broad coalition government with a specific distribution of the seven government seats among them: Two seats were assigned, respectively, to the liberal Radical Free Democratic Party, the Christian Democratic People's Party, and the Social Democratic Party, while one seat was given to the conservative Farmers' Party, which later became the Swiss People's Party. At that time, the allotments corresponded roughly to the relative shares of votes of these parties. As a remarkable matter of fact, the 1959 allocation of seats on the Federal Council continued unaltered for 44 years. It is therefore referred to as Switzerland's 'Magic Formula'. In 2003, however, the Christian Democrats lost one government seat to the Swiss People's Party which had in the meantime grown to be the strongest party in the Federal Assembly. The revised formula was thereafter confirmed again most recently in 2007. Even so, the four governing parties never signed a written coalition agreement or joint political program.

The Federal Council, when in session, acts as a collegial body and by majority accord, without explicit vote-taking whenever possible in practice. The Councillors, then, are expected to support all Council decisions vis-à-vis the public, independent of their own conviction or that of their parties. To this effect, as a rule, Federal Councillors are not supposed to criticize one another in open court. In turn, almost all sitting Councillors ever since 1959 have been re-elected once, twice, or even three times, routinely on the first ballot, and often with more than $80 \%$ up to around $90 \%$ of the vote total. Councillors who decided to step down were replaced without trouble. In 1999, e.g., the two Christian Democrats in the Federal Council resigned from their offices before the end of term, each Councillor after 12 years of service. It took the parliament four rounds of voting to fill the first seat, while six rounds were needed to fill the second. Nonetheless, in the respective two opening rounds, as much as $88 \%, 99 \%$, and at two times even $100 \%$ of the votes cast were already won by members of the Christian Democratic People's Party. These figures are evidence of a robust 
commitment to the Magic Formula across all parties represented in the parliament. The parties thus also seem largely to be engaged in bloc voting, although every party delegate votes without binding instructions.

The Magic Formula has greatly contributed to Switzerland's historical political stability, and thereby also to the country's economic performance. The Formula owes this success to the pursuit of 'concordance' in many areas of politics. The term is commonly used to describe a strong preference for cooperative conflict resolution. As to the Federal Council, many of the Council's legislative drafts on important matters such as, e.g., public finances, justice reform, telecommunications, railroad transportation, and environmental protection enjoyed the far-reaching consent of all political parties in the National Council and in the Council of States. Even more, concordance signifies a Rawlsian (1971) concern for minorities. To put it in the words of the Preamble to the Constitution of the Swiss Confederation (2010): "The Swiss People and the Cantons, ... in the knowledge ... that the strength of a people is measured by the well-being of its weakest members ...". From the point of view of modern social choice theory (e.g., Arrow et al. 2002; Moulin 1988, 2003; Young 1994), such a constitutional declaration seems to presuppose a lexicographic welfare ordering for the Swiss society. In the present paper, we raise the question whether this conclusion may be substantiated empirically, and above all, for the distribution of representation in Switzerland's highest governing authority, i.e., for the composition of the Swiss Federal Council. In particular, we explore the extent to which the Magic Formula can be implemented by a weighted voting game, where the parties in the Federal Assembly are considered as the players. The game will be solved in terms of the nucleolus, a fundamental lexicographic solution concept for cooperative games. We shall argue that this concept can be motivated in our game both by intuition and by reasonable axioms. ${ }^{1}$ The paper can thus be seen as an application of the theory of cooperative games to political science.

The subsequent work is organized as follows: Our weighted voting game for the Swiss Federal Council will be developed in Sect. 2. There we also present our data set for 13 elections to the Federal Council between 1959 and 2007. Section 3 is devoted to the nucleolus as a game-theoretic concept and to important properties of this concept which are relevant to our game. The game solution for real-valued and integer-valued imputation sets is presented in Sect. 4. We shall see, in particular, that the Magic Formula is contained in eight out of 11 nucleoli over integer domains between 1959 and 1999, and that it comes very close to the nucleolus in two of the three remaining cases. The nucleoli associated with the 2003 and 2007 elections to the Federal Council support the 2003 revision of the Magic Formula with respect to the Christian Democratic People's Party and the Swiss People's Party. However, starting from the 1999 election, our game solution also assigns a government seat to the Green Party, in place of a seat of the Christian Democrats in 1999 and the Radical Free Democrats in 2003 and 2007. Section 5 concludes with a summary and a brief outlook on the future prospects of the Magic Formula.

\section{A game of voting for the Swiss Federal Council}

To begin with, we define as $N:=\{1, \ldots, n\}$ the finite set of all $n$ political parties which are represented in the Swiss Federal Assembly after each full renewal of the National Council every four years, starting from the election period 1959. These parties will be interpreted

\footnotetext{
${ }^{1}$ Also cf. Montero (2005) who proposes the nucleolus as a measure of voting power.
} 
Table 1 Allocation of seats in the Federal Assembly

\begin{tabular}{|c|c|c|c|c|c|c|c|c|c|c|c|c|c|}
\hline \multirow[t]{2}{*}{ Party } & \multicolumn{13}{|l|}{ Year } \\
\hline & 1959 & 1963 & 1967 & 1971 & 1975 & 1979 & 1983 & 1987 & 1991 & 1995 & 1999 & 2003 & 2007 \\
\hline FDP & 65 & 64 & 63 & 64 & 62 & 62 & 68 & 65 & 62 & 62 & 61 & 50 & 43 \\
\hline CDP & 65 & 66 & 63 & 61 & 63 & 62 & 60 & 61 & 52 & 50 & 50 & 43 & 46 \\
\hline SDP & 53 & 56 & 52 & 50 & 60 & 60 & 53 & 47 & 46 & 59 & 57 & 61 & 52 \\
\hline SPP & 27 & 26 & 24 & 28 & 26 & 28 & 28 & 29 & 29 & 34 & 51 & 63 & 69 \\
\hline GP & - & - & - & - & - & 1 & 4 & 9 & 14 & 8 & 9 & 13 & 22 \\
\hline \multirow[t]{10}{*}{ Other } & 10 & 10 & 17 & 14 & 12 & 11 & 11 & 12 & 13 & 9 & 6 & 4 & 4 \\
\hline & 8 & 9 & 9 & 11 & 7 & 8 & 9 & 10 & 8 & 7 & 3 & 3 & 4 \\
\hline & 6 & 7 & 6 & 8 & 6 & 3 & 5 & 3 & 6 & 4 & 3 & 2 & 2 \\
\hline & 3 & 4 & 5 & 5 & 4 & 3 & 3 & 3 & 5 & 3 & 2 & 2 & 1 \\
\hline & 2 & 2 & 3 & 3 & 3 & 3 & 3 & 3 & 3 & 3 & 1 & 1 & 1 \\
\hline & 1 & - & 1 & - & 1 & 2 & 1 & 2 & 3 & 2 & 1 & 1 & 1 \\
\hline & - & - & 1 & - & - & 2 & 1 & 1 & 2 & 2 & 1 & 1 & 1 \\
\hline & - & - & - & - & - & 1 & - & 1 & 1 & 1 & 1 & 1 & - \\
\hline & - & - & - & - & - & - & - & - & 1 & 1 & - & 1 & - \\
\hline & - & - & - & - & - & - & - & - & 1 & 1 & - & - & - \\
\hline Total & 240 & 244 & 244 & 244 & 244 & 246 & 246 & 246 & 246 & 246 & 246 & 246 & 246 \\
\hline
\end{tabular}

FDP: Radical Free Democratic Party, CDP: Christian Democratic People's Party, SDP: Social Democratic Party, SPP: Swiss People's Party, GP: Green Party, Other: By number of seats

as the players in the election of Switzerland's government, i.e., of the Federal Council. Their number $n$ ranges from nine to 15 . Each subset $S$ of $N$ is called a coalition, ${ }^{2}$ and no coalition of two or more parties shall be excluded a priori for reasons of political ideology. In other words, we do not impose any constraints on coalition formation. Every party or player $i$ casts the $w_{i}>0$ single votes of the party's delegates in the parliament. We always assume that all parliament members participate in an election. The vote total $w:=\sum_{i=1}^{n} w_{i}$ then amounts to either 240,244 , or 246 , depending on the number of available parliament seats. ${ }^{3}$ The respective quotas needed to elect a Council member can be calculated from $q:=w / 2+1$, which implements the absolute majority rule. We are thus given a game $\left[q ; w_{1}, \ldots, w_{n}\right]$ of weighted voting (cf. von Neumann and Morgenstern 1947, pp. 431-433) to fill the seven Council seats.

The empirical distribution of seats in the Federal Assembly over the 1959-2007 time period is provided in Table 1. The seats of the four governing parties are listed with explicit party reference. We also explicitly report the number of seats of the Green Party which has become the next strongest party in the parliament. The remaining seats were won by various collections of other parties. These parties are recorded only by their numbers of parliamentary seats, in descending order, and therefore a row of table entries can no longer be related to a single party.

\footnotetext{
${ }^{2}$ Our concept of a coalition shall include $N$ itself (the grand coalition of all parties) as well as every singleparty 'coalition' $\{i\}, i \in N$, and the empty 'coalition' $\emptyset$.

${ }^{3}$ This number was increased twice after 1959 in an adjustment to population growth and due to the creation of a new Federal State (Canton).
} 
It will be convenient to study the coalitional game $\Gamma:=(N, v)$ and its characteristic function $v: 2^{N} \rightarrow\{0,7\}$ associated with $\left[q ; w_{1}, \ldots, w_{n}\right]$. For all coalitions $S \subseteq N, S \neq \emptyset: 4$

$$
v(S)= \begin{cases}7 & \text { if } \sum_{i \in S} w_{i} \geq q, \\ 0 & \text { otherwise. }\end{cases}
$$

A coalition $S$ with $v(S)=7$ is called a winning coalition. If $v(S)=0$, coalition $S$ is said to be losing. Whenever a winning coalition forms, it may freely decide how to share its worth $v(S)$, i.e., how to allocate all government seats. By convention, $v(\emptyset)=0$ for the empty 'coalition'. The game is proper, since $q>w / 2$, which means that there are no two disjoint winning coalitions of players who could then pass contradictory propositions: $v(S)=7 \Rightarrow$ $v(N \backslash S)=0$. We note that $\Gamma$ belongs to the family of simple games (cf. von Neumann and Morgenstern 1947, Chap. 10; Shapley 1962), as the union $S \cup T$ of a winning coalition $S$ and any disjoint coalition $T$ always results in a winning coalition.

An outcome of the coalitional game $\Gamma$ is an $n$-tuple $\mathbf{x}:=\left(x_{1}, \ldots, x_{n}\right)$, where $x_{i}$ is the number of government seats assigned to party $i$. The problem then is to select at least one such outcome from the game's imputation set, i.e., from the set of all feasible assignments of the seven government seats. This set will be real-valued, if a government seat can be shared by two or more players. The fractional part of $x_{i}$ will then be interpreted as one seat given to party $i$ for the respective fractional part of a regular term of office. We are, in contrast, concerned with an integer allocation problem (cf. Young 1994, pp. 184-190), if the seats are by assumption indivisible. Both cases will be considered in more detail in the next sections. The appropriate imputation set will be denoted as $X^{0}:=\left\{\mathbf{x} \in \mathbb{R}_{\geq 0}^{n}: \sum_{i \in N} x_{i}=7\right\}$ and $X^{1}:=\left\{\mathbf{x} \in \mathbb{Z}_{\geq 0}^{n}: \sum_{i \in N} x_{i}=7\right\}$, respectively. ${ }^{5,6}$ Elements of $X^{0}$ or $X^{1}$ will be called a payoff configuration or simply a payoff for the game $\Gamma$.

\section{The nucleolus over $X^{0}$ and $X^{1}$}

As we have argued earlier, the Swiss political paradigm of concordance is essentially egalitarian, with a Rawlsian (1971) focus on the least favored. The nucleolus also minimizes disadvantage and thus appears to be an appropriate solution concept for $\Gamma$. This section offers a more elaborate rationale for such a choice. We start with some notation and a formal definition.

Assume that an arbitrary payoff $\mathbf{x}$ has been proposed. We define the excess of coalition $S \subset N, S \neq \emptyset$, at $\mathbf{x}$ as $e(S, \mathbf{x}):=v(S)-\sum_{i \in S} x_{i}$. If $e(S, \mathbf{x})>0$, then coalition $S$ is better off by standing alone instead of accepting $\mathbf{x}$. Hence, each excess $e(S, \mathbf{x})$ can be interpreted as a measure of discontent (or content, if negative) of coalition $S$ when faced with proposal $\mathbf{x}$. Now associate with each payoff $\mathbf{x}$ the (complaint) vector $\Theta(\mathbf{x})$ of all $2^{n}-2$ excesses $e(S, \mathbf{x})$, arranged in decreasing (or nonincreasing) magnitude. Then, the nucleolus is the set of all

\footnotetext{
${ }^{4}$ The symbol $\subseteq$ indicates weak set inclusion. Our notation for strict (proper) set inclusion is $\subset$.

${ }^{5}$ We denote as $\mathbb{R}_{\geq 0}^{n}$ and, correspondingly, as $\mathbb{Z}_{\geq 0}^{n}$, the $n$-dimensional Euclidean spaces of all nonnegative real numbers and of all nonnegative integers.

${ }^{6}$ For the purpose of illustration, let $n=2$. The set $X^{0}$ then is a straight line in $\mathbb{R}_{\geq 0}^{2}$ from $(0,7)$ to $(7,0)$. The resulting set of points with integer coordinates along this line constitutes $X^{1}$, whereby $X^{1}=$ $\{(0,7),(1,6),(2,5), \ldots,(7,0)\}$.
} 
payoff configurations which are most acceptable in the sense that they minimize $\Theta(\mathbf{x})$ lexicographically over the set of admissible payoffs: ${ }^{7}$

Definition 1 The nucleolus $\mathcal{N}(\Gamma, X)$ of the game $\Gamma$ with respect to the set $X \in\left\{X^{0}, X^{1}\right\}$ is given by

$$
\mathcal{N}(\Gamma, X):=\left\{\mathbf{x} \in X: \Theta(\mathbf{x}) \leq_{l e x} \Theta(\mathbf{y}) \text { for all } \mathbf{y} \in X\right\} .
$$

It contains all payoffs $\mathbf{x} \in X$ for which $\Theta(\mathbf{x})$ is lexicographically least.

It can be shown that $\mathcal{N}(\Gamma, X) \neq \emptyset$ for both $X=X^{0}$ and $X=X^{1}$, since $X^{0}$ and $X^{1}$ are nonempty and compact sets. Furthermore, as the set $X^{0}$ is also convex, $\mathcal{N}\left(\Gamma, X^{0}\right)$ will always consist of a unique payoff configuration, the so-called nucleolus point of the game $\Gamma$. (Cf. Schmeidler $1969 .^{8}$ )

The leximin operator in (2) can be motivated intuitively by a scenario of egalitarian arbitration among coalitions of players. We quote from Maschler (1992, p. 611):

Consider an arbitrator, whom the players ask to decide how to share $v(N)[=7]$. The arbitrator may regard the excess of a coalition as a measure of dissatisfaction and he may be eager to decrease the excesses of the various coalitions as much as possible. ... He will then look for payoffs in which the highest excess is as low as possible. If there is more than one such payoff, he will tell the highest-excess coalitions: "I have helped you as much as I could, but I can still help other coalitions." He will then proceed to choose outcomes for which the second highest excess is minimal, and so on.

This parable illustrates, too, that the nucleolus is by definition an impartial solution concept. That is, only the excesses of the coalitions matter, independent of how the players are named or indexed. We shall now briefly address two deeper properties of the nucleolus which are also relevant to our application. One of them is a property of order preservation with respect to the votes of the players. The other, a reduced-game property, follows from a property of independence of irrelevant alternatives and is an integral part of various axiomatizations of the nucleolus in the literature (e.g., Sobolev 1975; Maschler et al. 1992).

A less obvious, but desirable feature of $\mathcal{N}(\Gamma, X)$ over both domains $X^{0}$ and $X^{1}$ is that it reflects the strength of a party in the Federal Assembly. More precisely:

Proposition 1 Each payoff vector $\mathbf{x}$ in the nucleolus $\mathcal{N}(\Gamma, X)$ of the game $\Gamma$ with respect to $X \in\left\{X^{0}, X^{1}\right\}$ satisfies:

(a) If $X=X^{0}$ and $w_{i} \geq w_{j}$, then $x_{i} \geq x_{j}$.

(b) If $X=X^{1}$ and $w_{i} \geq w_{j}$, then $x_{i} \geq x_{j}-1$.

\footnotetext{
${ }^{7}$ Excess vector $\Theta=\left(e_{1}, \ldots, e_{2^{n}-2}\right)$ is said to be lexicographically less than excess vector $\tilde{\Theta}=$ $\left(\tilde{e}_{1}, \ldots, \tilde{e}_{2^{n}-2}\right)$, if there exists an index $k$ such that $e_{i}=\tilde{e}_{i}$ for all $i<k$ and $e_{k}<\tilde{e}_{k}$. We write $\Theta<$ lex $\tilde{\Theta}$. If either $\Theta<_{l e x} \tilde{\Theta}$ or $\Theta=\tilde{\Theta}$, then we write $\Theta \leq_{l e x} \tilde{\Theta}$.

${ }^{8}$ Schmeidler's original definition of the nucleolus explicitly demands that $v(\{i\})=0$ and, hence, $x_{i} \geq v(\{i\})$ for all single players $i$. The latter inequalities ensure that the game solution is always individually rational. In our game, both requirements are met, as no single player has enough votes to gain a majority on his own, i.e., there is no 'dictator'.
} 
Proof Assume that there are two players $i$ and $j$ such that $w_{i} \geq w_{j}$. Hence, by (1), $v(S \cup$ $\{i\}) \geq v(S \cup\{j\})$ for all coalitions $S \subseteq N \backslash\{i, j\}{ }^{9}$ To begin with, suppose that $X=X^{0}$. Also suppose, per absurdum, that $\mathbf{x} \in \mathcal{N}\left(\Gamma, X^{0}\right)$ with $x_{i}<x_{j}$. Consequently, $e(S \cup\{i\}, \mathbf{x})>e(S \cup$ $\{j\}, \mathbf{x})$ for all coalitions $S \subseteq N \backslash\{i, j\}$. Now take any coalition $T \in \arg \max _{S \subseteq N \backslash\{i, j\}} e(S \cup$ $\{j\}, \mathbf{x})$ and define $\epsilon:=e(T \cup\{i\}, \mathbf{x})-e(T \cup\{j\}, \mathbf{x})>0$. Then consider a payoff transfer $\gamma \in(0, \epsilon / 2]$ from player $j$ to player $i$. This transfer reduces the excess of every coalition $Q_{i,-j} \in\{S \subseteq N \backslash\{j\}: i \in S\}$ by $\gamma$, while the excess of each coalition $Q_{j,-i} \in\{S \subseteq N \backslash$ $\{i\}: j \in S\}$ increases by this amount. The excesses of all other coalitions stay constant. Since $\gamma$ is small enough to weakly preserve the order of the excesses of coalitions $T \cup\{i\}$ and $T \cup\{j\}$, the resulting new vector of ordered excesses must be lexicographically less than $\Theta(\mathbf{x})$. Therefore, $\mathbf{x}$ cannot be an element of $\mathcal{N}\left(\Gamma, X^{0}\right)$, which proves part (a). If $X=X^{1}$, then $\gamma=1$ is the smallest possible transfer from player $j$ to player $i$. It weakly preserves the order of the excesses of coalitions $T \cup\{i\}$ and $T \cup\{j\}$ only if we had assumed, again per absurdum, that $\mathbf{x} \in \mathcal{N}\left(\Gamma, X^{1}\right)$ and $x_{i} \leq x_{j}-2$. This confirms part (b).

An implication of Proposition 1 is that parties or players with equal voting weights in the Federal Assembly (cf. Table 1) are treated symmetrically, as we will now demonstrate. This means that they receive the same payoff, whenever possible. In the integer allocation problem, however, it may happen, e.g., that three seats in the Federal Council are to be divided between two such players $i$ and $j$. Symmetry then means that this results in a balanced allocation, i.e., the payoffs of the two players differ by at most one seat (Young 1994, p. 185). In particular, if $\mathbf{x} \in \mathcal{N}\left(\Gamma, X^{1}\right)$ and $\left(x_{i}, x_{j}\right)=(1,2)$, then $\tilde{\mathbf{x}} \in \mathcal{N}\left(\Gamma, X^{1}\right)$ for the mirror image with $\left(\tilde{x}_{i}, \tilde{x}_{j}\right)=(2,1)$ and $\tilde{x}_{k}=x_{k}$ for all $k \neq i, j$. Hence, $\mathcal{N}\left(\Gamma, X^{1}\right)$ will be set-valued:

Corollary 1 Each payoff vector $\mathbf{x}$ in the nucleolus $\mathcal{N}(\Gamma, X)$ of the game $\Gamma$ with respect to $X \in\left\{X^{0}, X^{1}\right\}$ satisfies:

(a) If $X=X^{0}$ and $w_{i}=w_{j}$, then $x_{i}=x_{j}$.

(b) If $X=X^{1}$ and $w_{i}=w_{j}$, then $\left|x_{i}-x_{j}\right| \in\{0,1\}$.

Proof Since $w_{i}=w_{j}$ by assumption, both inequalities $w_{i} \geq w_{j}$ and $w_{j} \geq w_{i}$ are met at the same time. If $X=X^{0}$, it follows from Proposition 1(a) that $x_{i} \geq x_{j}$ and $x_{j} \geq x_{i}$. Therefore, $x_{i}=x_{j}$ as claimed. If $X^{0}$ is replaced by $X^{1}$, we conclude from Proposition 1 (b) that $x_{i} \geq$ $x_{j}-1$ and $x_{j} \geq x_{i}-1, x_{i}$ and $x_{j}$ being integers. Accordingly, $\left|x_{i}-x_{j}\right| \in\{0,1\}$.

The logic for a set-valued $\mathcal{N}\left(\Gamma, X^{1}\right)$ also applies if $w_{i} \neq w_{j}$, as long as $\left|w_{i}-w_{j}\right|$ is sufficiently small, i.e., if still $v(S \cup\{i\})=v(S \cup\{j\})$ for all coalitions $S \subseteq N \backslash\{i, j\}$. It accounts for cases where $w_{i}>w_{j}$, but $x_{i}=x_{j}-1$ in $\mathbf{x} \in \mathcal{N}\left(\Gamma, X^{1}\right)$. Then again, $\tilde{\mathbf{x}} \in \mathcal{N}\left(\Gamma, X^{1}\right)$ with $\left(\tilde{x}_{i}, \tilde{x}_{j}\right)=\left(x_{j}, x_{i}\right)$ and $\tilde{x}_{k}=x_{k}$ for all $k \neq i, j$.

It remains to show that $\mathcal{N}(\Gamma, X)$ has a reduced-game property that is relevant to our application. This property is a special case of a property of independence of irrelevant alternatives. As before, $X \in\left\{X^{0}, X^{1}\right\}$ :

Proposition 2 If $X^{\prime} \subseteq X$ and $\mathcal{N}(\Gamma, X) \cap X^{\prime} \neq \emptyset$, then $\mathcal{N}\left(\Gamma, X^{\prime}\right)=\mathcal{N}(\Gamma, X) \cap X^{\prime}{ }^{10}$

\footnotetext{
${ }^{9}$ No such coalition $S$ will prefer player $j$ to player $i$ as a partner. Player $i$ is thus said to be at least as desirable as player $j$ (e.g., Maschler 1992, p. 606; Peleg and Sudhölter 2003, p. 119).

${ }^{10}$ A weaker requirement is the following: If $X^{\prime} \subseteq X$ and $\emptyset \neq \mathcal{N}(\Gamma, X) \subseteq X^{\prime}$, then $\mathcal{N}\left(\Gamma, X^{\prime}\right)=\mathcal{N}(\Gamma, X)$. This one applies, e.g., if $\mathcal{N}(\Gamma, X)$ is a singleton. Maschler et al. (1992, pp. 89-90) derive both versions of independence of irrelevant alternatives from a stronger property which they call contravariance.
} 
Proof Let $Y:=\mathcal{N}(\Gamma, X) \cap X^{\prime}$. By assumption, $Y \neq \emptyset$. As $Y \subseteq \mathcal{N}(\Gamma, X)$ by definition of $Y$, every excess vector $\Theta(\mathbf{y})$ with $\mathbf{y} \in Y$ is lexicographically least over $X$. Hence, we cannot arrive at a smaller excess vector by restricting the set of admissible payoffs to $X^{\prime}$. Therefore, since also $Y \subseteq X^{\prime}$ by definition of $Y$, we conclude that $Y \subseteq \mathcal{N}\left(\Gamma, X^{\prime}\right) \neq \emptyset$. Now suppose that there is an element $\mathbf{x} \in \mathcal{N}\left(\Gamma, X^{\prime}\right)$ which is not contained in $Y$. Then, $\Theta(\mathbf{x})=\Theta(\mathbf{y})$ for each $\mathbf{y} \in Y$. Consequently, $\mathbf{x} \in X^{\prime}$ and $\mathbf{x} \in \mathcal{N}(\Gamma, X)$, which contradicts the assumption that $\mathbf{x}$ does not belong to $Y$. In all, $\mathcal{N}\left(\Gamma, X^{\prime}\right)=Y$.

Suppose that $X^{\prime}$ is generated from $X$ in that we take a nonempty coalition $S \subseteq N$ of players and freeze the payoffs of the remaining players at $\mathbf{x} \in \mathcal{N}(\Gamma, X)$. We are in this way concerned with admissible payoffs $\mathbf{x}^{\prime} \in X^{\prime}$ such that $x_{i}^{\prime}=x_{i}$ for all players $i \notin S$. Now consider any nonempty coalition $T \subset S$ and an arbitrary partner coalition $R \subseteq N \backslash S$. Then, $e\left(T \cup R, \mathbf{x}^{\prime}\right)=v(T \cup R)-\sum_{i \in T} x_{i}^{\prime}-\sum_{i \in R} x_{i}{ }^{11}$ Note that $v(T \cup R)-\sum_{i \in R} x_{i}$ does not depend on the payoffs $x_{i}^{\prime}, i \in S$, while the deduction $-\sum_{i \in T} x_{i}^{\prime}$ is the same for all such $T \cup R$, no matter which partner coalition $R$ has been selected. An arbitrator would then want to deduct from $\max _{R \subseteq N \backslash S}\left\{v(T \cup R)-\sum_{i \in R} x_{i}\right\}$ as much as possible. We are thus given a hypothetical reduced game $\left(S, v_{S}^{\mathbf{x}}\right)$ (cf. Davis and Maschler 1965), defined on a subset of players $S$ at the payoff vector $\mathbf{x}$, with characteristic function

$$
v_{S}^{\mathbf{x}}(T)= \begin{cases}\max _{R \subseteq N \backslash S}\left\{v(T \cup R)-\sum_{i \in R} x_{i}\right\}, & \text { if } \emptyset \neq T \subset S, \\ \sum_{i \in T} x_{i}, & \text { if } T \in\{S, \emptyset\} .\end{cases}
$$

An interpretation of $\left(S, v_{S}^{\mathbf{x}}\right)$ is that the players in $S$ examine their 'own' game, once the other players have accepted their payoffs in $\mathbf{x}$. As these other players are still available for coalition formation, each nonempty subset of players in $S$ would look for a best partner coalition $R$ that it could possibly buy out at $\sum_{i \in R} x_{i}$ and claim the resulting net worth as in (3). ${ }^{12}$ In our application, one might think of a Federal Council that is to be partly renewed, as in 1999, when the two Christian Democrats in the Federal Council resigned ahead of time. According to Proposition 2, the payoffs of the players in the reduced game will not be redistributed then. This can be seen as an element of stability in the original game as well as indication of logical coherence of our solution concept. We may thus say that an allocation $\mathbf{x} \in \mathcal{N}(\Gamma, X)$ of Council seats is consistent.

\section{Results}

An efficient numerical algorithm for the computation of the nucleolus point of a weighted voting game over a real-valued imputation set like $X^{0}$ has been proposed by Wolsey (1976). We applied this algorithm to find $\mathcal{N}\left(\Gamma, X^{0}\right)$ for every full renewal of the Federal Council from 1959 to date, given the information in Table 1 above. All calculations have been performed in an extended-precision floating-point format that offers 18 significant digits. A modern Personal Computer can perform such a task in less than a second of computing time per election period. Our (rounded) results are provided in Table 2. This table reports

\footnotetext{
${ }^{11}$ By convention, $\sum_{i \in R} x_{i}=0$ if $R=\emptyset$.

${ }^{12}$ Some of these partner coalitions might even overlap across different subsets of $S$. Cf. Maschler (1992, pp. 617-618) for a discussion of this aspect.
} 
Table 2 Nucleolus over the domain $X^{0}$

\begin{tabular}{|c|c|c|c|c|c|c|c|c|c|c|c|c|c|}
\hline \multirow[t]{2}{*}{ Party } & \multicolumn{13}{|l|}{ Year } \\
\hline & 1959 & 1963 & 1967 & 1971 & 1975 & 1979 & 1983 & 1987 & 1991 & 1995 & 1999 & 2003 & 2007 \\
\hline FDP & 1.83 & 1.67 & 1.78 & 1.85 & 2.33 & 1.80 & 1.94 & 1.84 & 1.76 & 1.77 & 1.72 & 1.11 & 0.95 \\
\hline CDP & 1.83 & 2.00 & 1.78 & 1.75 & 2.33 & 1.80 & 1.61 & 1.69 & 1.47 & 1.28 & 1.02 & 0.72 & 1.13 \\
\hline SDP & 1.52 & 1.67 & 1.36 & 1.34 & 2.33 & 1.60 & 1.48 & 1.25 & 1.29 & 1.65 & 1.46 & 1.72 & 1.48 \\
\hline SPP & 0.30 & 0.33 & 0.42 & 0.51 & 0 & 0.20 & 0.45 & 0.59 & 0.78 & 0.62 & 1.08 & 1.83 & 1.90 \\
\hline GP & - & - & - & - & - & 0.10 & 0.16 & 0.33 & 0.42 & 0.33 & 0.57 & 0.72 & 0.71 \\
\hline \multirow[t]{10}{*}{ Other } & 0.30 & 0.33 & 0.42 & 0.51 & 0 & 0.20 & 0.45 & 0.44 & 0.39 & 0.37 & 0.38 & 0.22 & 0.24 \\
\hline & 0.30 & 0.33 & 0.42 & 0.41 & 0 & 0.20 & 0.37 & 0.37 & 0.24 & 0.29 & 0.19 & 0.17 & 0.24 \\
\hline & 0.30 & 0.33 & 0.30 & 0.31 & 0 & 0.20 & 0.21 & 0.11 & 0.18 & 0.16 & 0.19 & 0.11 & 0.12 \\
\hline & 0.30 & 0.33 & 0.24 & 0.21 & 0 & 0.20 & 0.12 & 0.11 & 0.15 & 0.12 & 0.13 & 0.11 & 0.06 \\
\hline & 0.30 & 0 & 0.18 & 0.10 & 0 & 0.20 & 0.12 & 0.11 & 0.09 & 0.12 & 0.06 & 0.06 & 0.06 \\
\hline & 0 & - & 0.06 & - & 0 & 0.20 & 0.04 & 0.07 & 0.09 & 0.08 & 0.06 & 0.06 & 0.06 \\
\hline & - & - & 0.06 & - & - & 0.20 & 0.04 & 0.04 & 0.06 & 0.08 & 0.06 & 0.06 & 0.06 \\
\hline & - & - & - & - & - & 0.10 & - & 0.04 & 0.03 & 0.04 & 0.06 & 0.06 & - \\
\hline & - & - & - & - & - & - & - & - & 0.03 & 0.04 & - & 0.06 & - \\
\hline & - & - & - & - & - & - & - & - & 0.03 & 0.04 & - & - & - \\
\hline
\end{tabular}

FDP: Radical Free Democratic Party, CDP: Christian Democratic People's Party, SDP: Social Democratic Party, SPP: Swiss People's Party, GP: Green Party, Other: As in Table 1

the numbers of seats (including fractions thereof) that are allocated to each of the four governing parties and to the Green Party, as well as the seats assigned to the smaller parties classified as 'other'. ${ }^{13}$

We conclude from Table 2 that the four governing parties in total are already allocated between 5.28 seats (1999) and as much as 7.00 seats (1975). ${ }^{14}$ The average total allotment over the 13 elections amounts to 5.53 seats. The shares in this average are 1.72 seats for the Radical Free Democratic Party (FDP), 1.57 seats for the Christian Democratic People's Party (CDP), 1.55 seats for the Social Democratic Party (SDP), and 0.69 seats for the Swiss People's Party (SDP). As can be seen from the final three columns of Table 2, the Radical Free Democrats and the Christian Democrats are assigned far-below-average shares of government seats for the last two and last three elections, respectively. The decline in the share of the latter party can be traced back further to the 1991 election. In turn, the share of the conservative Swiss People's Party grows almost continuously, starting from the year 1979. These figures for the governing parties reflect major changes in the numbers of votes of these parties in the Federal Assembly over time (cf. Table 1). Other than that, at most 1.72 $(=7-5.28)$ seats $(1999)$ per election are allocated to the non-governmental smaller parties

\footnotetext{
${ }^{13}$ Small deviations of the column sums of Table 2 from seven, i.e., from the overall number of seats in the Federal Council, are due to rounding.

${ }^{14}$ Note for the year 1975 that $q=123$, while $w_{1}=62$ (FDP), $w_{2}=63$ (CDP), and $w_{3}=60$ (SDP) (cf. Table 1). Hence, there are already two winning coalitions of size 2 (coalitions $\{F D P, C D P\}$ and $\{C D P, S D P\}$ ), while each of the first three parties belongs to at least one such coalition. Also, no coalition of one of these parties alone with even all of the seven remaining parties is winning.
} 
in total, ${ }^{15}$ with an average of 1.47 seats. The concerned parties always receive fractions of a government seat which range from negligible up to the smallest share of a governing party. As to the 1999-2007 elections, by far the largest fractions go to the Green Party (GP). The 2003 fraction of the Greens even matches the respective share of the Christian Democrats. In all, as may be expected from a lexicographic game solution, the nucleolus point $\mathcal{N}\left(\Gamma, X^{0}\right)$ puts some emphasis on parties with fewer votes.

The fractional part of a government seat in Table 2 can be interpreted as a seat in the Federal Council that is assigned to a party only for this fractional part of a regular term of office. At least one other party will then have to take over during the remainder of the term. We could argue that a Federal Councillor is, indeed, free to step down ahead of time. The vacant council seat could, thereby, also be transferred to another party. However, such a transfer during a normal term of function has never occurred in practice since 1959. It also does not appear to be in the spirit of the Swiss Constitution. This can already be seen from the fact that the parliament has no power to dismiss a sitting Councillor. Article 145 of the Constitution (cf. Swiss Confederation 2010), in particular, states that the "members of ... the Federal Council ... shall be elected for a term of office of four years." From this perspective, a government seat in reality will not be shared between various parties. Put differently, every government seat is by assumption indivisible, which leaves us with an integer allocation problem.

We solved this problem in that we calculated the nucleolus directly over the integervalued domain $X^{1}$, which then also provides us with an integer-valued game solution, this solution being $\mathcal{N}\left(\Gamma, X^{1}\right)$. As we are not aware of an algorithm that would allow us to compute $\mathcal{N}\left(\Gamma, X^{1}\right)$, we proceeded as follows. We first enumerated the complete sets $X^{1}$ of nonnegative integer allocations of the seven government seats to $9,10, \ldots, 15$ parties in the Federal Assembly. For every election to the Federal Council, then, we evaluated the vector of ordered excesses over the relevant set $X^{1}$ and collected those elements of $X^{1}$ for which this vector is lexicographically minimal, again based on the information in Table 1 . This can be done entirely in integer arithmetic. Given $X^{1}$, a modern Personal Computer will need from about a second up to roughly three quarters of a minute of computing time to determine $\mathcal{N}\left(\Gamma, X^{1}\right)$, depending on the number of parties. The results are listed in Table 3. Numbers in italics indicate that the nucleolus is not a singleton. In all such cases, the government seat of the Swiss People's Party (SPP) is re-assigned to at least one player from the group of smaller parties tabulated as 'other'. As an example, the 1959 nucleolus is given by the set $\{(2,2,2,1,0,0,0,0,0,0),(2,2,2,0,1,0,0,0,0,0), \ldots,(2,2,2,0,0,0,0,1,0,0)\}$. Each of its five elements is associated with the same (lexicographically smallest) vector of ordered excesses, and has been taken from the set of nonnegative integer allocations of the seven government seats to a total of 10 parties.

As a first remarkable result, Table 3 shows that the Magic Formula $(2,2,2,1,0, \ldots, 0)$ is immediately contained in $\mathcal{N}\left(\Gamma, X^{1}\right)$ for as many as eight of 11 regular election years during the time period 1959-1999, when the Magic Formula was, in fact, applied. It is moreover the only element of $\mathcal{N}\left(\Gamma, X^{1}\right)$ for the years 1987,1991 , and 1995 . The respective two government seats of the Radical Free Democratic Party (FDP) and the Social Democratic Party (SDP), in particular, are never contested for all regular elections to the Federal Council between 1959 and 1999. The two Council seats of the latter party even remain uncontested for all years in the data set. However, the seat of the Swiss People's Party (SPP) is reallocated in $\mathcal{N}\left(\Gamma, X^{1}\right)$ several times to various smaller parties with comparably few votes in

\footnotetext{
${ }^{15}$ Addition of the relevant entries in the 1999 column of Table 2 produces a slightly smaller figure, because of minor rounding errors.
} 
Table 3 Nucleolus over the domain $X^{1}$

\begin{tabular}{|c|c|c|c|c|c|c|c|c|c|c|c|c|c|}
\hline \multirow[t]{2}{*}{ Party } & \multicolumn{13}{|l|}{ Year } \\
\hline & 1959 & 1963 & 1967 & 1971 & 1975 & 1979 & 1983 & 1987 & 1991 & 1995 & 1999 & 2003 & 2007 \\
\hline FDP & 2 & 2 & 2 & 2 & 2 & 2 & 2 & 2 & 2 & 2 & 2 & 1 & 1 \\
\hline CDP & 2 & 3 & 2 & 2 & 3 & 2 & 2 & 2 & 2 & 2 & 1 & 1 & 1 \\
\hline SDP & 2 & 2 & 2 & 2 & 2 & 2 & 2 & 2 & 2 & 2 & 2 & 2 & 2 \\
\hline SPP & 1 & 0 & 1 & 1 & 0 & 1 & 1 & 1 & 1 & 1 & 1 & 2 & 2 \\
\hline GP & - & - & - & - & - & 0 & 0 & 0 & 0 & 0 & 1 & 1 & 1 \\
\hline \multirow[t]{10}{*}{ Other } & 1 & 0 & 1 & 1 & 0 & 1 & 1 & 0 & 0 & 0 & 0 & 0 & 0 \\
\hline & 1 & 0 & 1 & 0 & 0 & 1 & 0 & 0 & 0 & 0 & 0 & 0 & 0 \\
\hline & 1 & 0 & 0 & 0 & 0 & 1 & 0 & 0 & 0 & 0 & 0 & 0 & 0 \\
\hline & 1 & 0 & 0 & 0 & 0 & 1 & 0 & 0 & 0 & 0 & 0 & 0 & 0 \\
\hline & 0 & 0 & 0 & 0 & 0 & 1 & 0 & 0 & 0 & 0 & 0 & 0 & 0 \\
\hline & 0 & - & 0 & - & 0 & 1 & 0 & 0 & 0 & 0 & 0 & 0 & 0 \\
\hline & - & - & 0 & - & - & 1 & 0 & 0 & 0 & 0 & 0 & 0 & 0 \\
\hline & - & - & - & - & - & 0 & - & 0 & 0 & 0 & 0 & 0 & - \\
\hline & - & - & - & - & - & - & - & - & 0 & 0 & - & 0 & - \\
\hline & - & - & - & - & - & - & - & - & 0 & 0 & - & - & - \\
\hline
\end{tabular}

FDP: Radical Free Democratic Party, CDP: Christian Democratic People's Party, SDP: Social Democratic Party, SPP: Swiss People's Party, GP: Green Party, Other: As in Table 1

the Federal Assembly. We thus find that the integer game solution also adds weight to these parties. In contrast, the Christian Democratic People's Party (CDP) in two cases (1963 and 1975) receives a third government seat, although its vote total in the Federal Assembly exceeds the vote total of the Radical Free Democrats by no more than one (1975) and two (1963). As to the 1963 election, our computations show that a transfer of just a single vote from the Christian Democrats to whichever party other than the Social Democratic Party would already suffice to re-establish the Magic Formula in the game outcome. In the 1975 case, a transfer of only one vote each of the Christian and Social Democrats to the group of non-governmental parties would produce the same effect. Hence, the Magic Formula comes very close to the 1963 and 1975 nucleoli, although it is not fully contained in them. For all other years during the time period 1959-1999, except for the year 1999 itself, the two seats assigned to the Christian Democrats by the Magic Formula are supported under $\mathcal{N}\left(\Gamma, X^{1}\right)$.

Another essential feature of $\mathcal{N}\left(\Gamma, X^{1}\right)$ is that it suggests that the number of government seats of the Christian Democratic People's Party be cut from two to one starting from 1999. At that time, indeed, such a cut became an item on Switzerland's political agenda. The reason for this is that the number of votes of the Christian Democrats in the Federal Assembly had fallen short of the number of votes of the Swiss People's Party for the first time since 1959. Soon thereafter, in the next regular election year 2003, the Christian Democrats lost their second seat in the Federal Council to the Swiss People's Party, according to the revised formula $(2,1,2,2,0, \ldots, 0)$. This transfer of executive representation from one party to another is supported by our game solution, inasmuch as $\mathcal{N}\left(\Gamma, X^{1}\right)$ gives an extra government seat to the Swiss People's Party for the years 2003 and 2007, while the Christian Democrats forfeit one seat.

Nevertheless, there is a major difference between the formula allocations for the most recent years 1999, 2003, and 2007, on the one hand, and the game solution on the other hand: 
The game solution repeatedly assigns a government seat to the Green Party! This party has become the strongest party in the Federal Assembly that is currently not represented in the Federal Council, also because it has not yet seriously claimed a government seat. The seat given to this party by $\mathcal{N}\left(\Gamma, X^{1}\right)$ comes at the cost of the Christian Democrats, at first. From 2003 on, and in view of the revised formula, the seat is taken away from the Radical Free Democrats. This is even more interesting as the Green Party had to suffer from a separation of some of its members who founded the Green Liberal Party, a party that won four more parliamentary seats in $2007 .{ }^{16}$

\section{Conclusion}

The purpose of this paper was to study the allocation of cabinet seats in Switzerland's Federal government, named the Federal Council. We started from the remarkable fact that there has been a stable empirical assignment of the seven Council seats to the same broad coalition of four governing parties for 44 years since 1959 according to the so-called Magic Formula. The underlying political paradigm of concordance appears to be essentially egalitarian, with a Rawlsian (1971) concern for the less favored, as mandated in the Preamble to the Constitution of the Swiss Confederation. Therefore, we asked whether the Magic Formula can be implemented by a lexicographic welfare ordering in terms of the nucleolus of a weighted voting game for the Federal Council, with the political parties in Switzerland's Federal Assembly as the players. We verified that the nucleolus would always reflect the strength of the players in such a game. We also confirmed that a reduced-game property would be satisfied, which we interpreted as a sign of consistency of a game solution and, thereby, as an element of stability. Based on these theoretical considerations, we computed the nucleolus of our voting game over real-valued and integer-valued imputation sets for all regular elections to the Federal Council from 1959 to date. It turned out that the game outcome places some emphasis on smaller parties, indeed. At the same time, however, the Magic Formula is contained in eight out of 11 nucleoli over integer domains between 1959 and 1999, when it was actually applied, and it comes very close to the nucleolus in two of the three remaining cases. The game solution likewise predicts in part a major revision of the Magic Formula adopted in 2003. Apart from that, in our results for the 1999, 2003, and 2007 government elections, and in contrast to the empirical composition of the Federal Council, the Green Party also receives a cabinet seat, at the expense of the Christian Democrats in 1999 and the Radical Free Democrats in 2003 and 2007.

In view of these results, we do not deny the fact that the game-theoretic approach has its limitations, as a look at the more recent political debate in Switzerland may reveal. During the 2007 elections to the Federal Council, the parliament chose not to re-elect one of the leaders of the Swiss People's Party as a Councillor for a second term of office. Another member of the same party from a cantonal government was elected to the Federal Council in place of him. Hence, this election respected the revised formula $(2,1,2,2,0, \ldots, 0)$ only numerically. The new Councillor was even not an official candidate of the Swiss People's Party. The era of concordance therefore seemed to have arrived at its closing stages. The Swiss People's Party announced that it would henceforth pursue its political objectives as an opposing party and with the instruments available to it from Switzerland's direct democracy. The party's Federal Councillors joined another, newly founded party. Yet, in late 2008, when

\footnotetext{
${ }^{16}$ In Table 1, the Green Liberal Party is one of seven 'other' parties which are reported in the column for the year 2007.
} 
one of them stepped down, the Swiss People's Party regained a Council seat. We will thus have to wait and see whether there will be a lasting agreement on a formula allocation of Switzerland's supreme executive power in the years to come.

Acknowledgements Earlier versions of this paper have been presented at the Fourth Spain Italy Netherlands Meeting on Game Theory (SING 4) in Wroclaw (2008) and at the Annual Meeting of the Swiss Society of Economics and Statistics in Geneva (2009). The authors wish to thank several conference participants and two anonymous referees for helpful comments. Support from the editor, William F. Shughart II, is also gratefully acknowledged.

\section{References}

Arrow, K. J., Sen, A. K., \& Suzumura, K. (Eds.) (2002). Handbook of social choice and welfare (Vol. 1). Amsterdam: North-Holland.

Balinsky, M. L., \& Young, H. P. (2001). Fair representation: meeting the ideal of one man, one vote (2nd edn.). Washington: Brookings Institution Press.

Brams, S. J. (1994). Voting procedures. In R. J. Aumann \& S. Hart (Eds.), Handbook of game theory with economic applications (Vol. 2, pp. 1055-1089). Amsterdam: North-Holland.

Brams, S. J., \& Fishburn, P. C. (2002). Voting procedures. In K. J. Arrow, A. K. Sen, \& K. Suzumura (Eds.), Handbook of social choice and welfare (Vol. 1, pp. 173-236). Amsterdam: North-Holland.

Davis, M., \& Maschler, M. (1965). The kernel of a cooperative game. Naval Research Logistics Quarterly, $12,223-259$.

Felsenthal, D. S., \& Machover, M. (1998). The measurement of voting power: theory and practice, problems and paradoxes. Cheltenham: Edward Elgar.

Holler, M. J., \& Owen, G. (Eds.) (2001). Power indices and coalition formation. Dordrecht: Kluwer.

Laruelle, A., \& Valenciano, F. (2008). Voting and collective decision-making: bargaining and power. Cambridge: Cambridge University Press.

Maschler, M. (1992). The bargaining set, kernel, and nucleolus. In R. J. Aumann \& S. Hart (Eds.), Handbook of game theory with economic applications (Vol. 1, pp. 591-667). Amsterdam: North-Holland.

Maschler, M., Potters, J. A. M., \& Tijs, S. H. (1992). The general nucleolus and the reduced game property. International Journal of Game Theory, 21, 85-106.

Montero, M. (2005). On the nucleolus as a power index. Homo Oeconomicus, 22, 551-567.

Moulin, H. (1988). Axioms of cooperative decision making. Cambridge: Cambridge University Press.

Moulin, H. (2003). Fair division and collective welfare. Cambridge: MIT Press.

Owen, G. (1995). Game theory (3rd edn.). San Diego: Academic Press.

Peleg, B. (2002). Game-theoretic analysis of voting in committees. In K. J. Arrow, A. K. Sen, \& K. Suzumura (Eds.), Handbook of social choice and welfare (Vol. 1, pp. 395-423). Amsterdam: North-Holland.

Peleg, B., \& Sudhölter, P. (2003). Introduction to the theory of cooperative games. Dordrecht: Kluwer.

Rawls, J. (1971). A theory of justice. Cambridge: Harvard University Press.

Schmeidler, D. (1969). The nucleolus of a characteristic function game. SIAM Journal on Applied Mathematics, $17,1163-1170$.

Shapley, L. S. (1962). Simple games: an outline of the descriptive theory. Behavioral Science, 7, 59-66.

Sobolev, A. I. (1975). Characterization of the principle of optimality for cooperative games by functional equations. In N. N. Voroby'ev (Ed.), Mathematical methods in the social sciences (Vol. 6, pp. 94-151). Vilnius: Academy of Sciences of the Lithuanian SSR. In Russian.

Swiss Confederation (2010). Federal Constitution of the Swiss Confederation of 18 April 1999. Available at http://www.admin.ch/org/polit/00083/index.html [August 24, 2010].

von Neumann, J., \& Morgenstern, O. (1947). Theory of games and economic behavior (2nd edn.). Princeton: Princeton University Press.

Wolsey, L. A. (1976). The nucleolus and the kernel for simple games or special valid inequalities for 0-1 linear integer programs. International Journal of Game Theory, 5, 227-238.

Young, H. P. (1994). Equity in theory and practice. Princeton: Princeton University Press. 